\title{
The synthesis of antioxidant enzymes in potato plants under biotic and abiotic stress conditions
}

\author{
I. Kirgizova ${ }^{1 *}$, A. Gajimuradova ${ }^{2}$, R. Omarov ${ }^{2}$ \\ ${ }^{1}$ Omsk State Technical University, Omsk, Russia \\ ${ }^{2}$ L.N. Gumilyov Eurasian National University, Astana, Kazakhstan \\ *e-mail:irina.kz-89@mail.ru
}

Key words: potato, superoxidedismutase, catalase, peroxidase, salt stress, viruses

Motivation and Aim: Potato is one of the important crops in the world. Many different viruses that can reduce yield and tuber quality can infect it. Infection of potato with virus and salinity stress leads to the generation of reactive forms of oxygen (ROS) and the development of an "oxidative burst". The high amount of ROS production is correlated by an equally high activation of antioxidant enzymes [1]. In some potato varieties, the levels of catalase, peroxidase and superoxide dismutase are enhanced with salinity, and it might alleviate the adverse effect of stress in potato [2].

Methods and Algorithms: The activity of catalase, superoxide dismutase and peroxidase were determined by spectrophotometric methods. Determination of the activity of antioxidant enzymes was carried out by native gel electrophoresis.

Results: The analysis of recent research investigation on the functional interaction of superoxide dismutase, catalase, peroxidase under the influence of viral infection and salinity stress significantly expanded the understanding of the mechanisms of early potato plant responses to stressful environmental conditions. Inoculation of potato with viruses $\mathrm{Y}$ and $\mathrm{S}$ combination with salinity $(10,20,30,40,50 \mathrm{mM} \mathrm{NaCl})$ stress lead to the high superoxide dismutase, catalase, peroxidase activities in potato.

Conclusion: Under salinity stress and $\mathrm{Y}$ and $\mathrm{S}$ virus infection the level of superoxide dismutase in Y-virus infected potato increased up to $31 \%$, in S-virus infected plants it enhanced up to $27 \%$, catalase level in Y-virus plants increased up to $43 \%$, in S-virus infected plants $-67 \%$, peroxidase activity in Y-virus infected plants was $33 \%$, in S-virus $-29 \%$. The results suggest that the Y-virus is more aggressive in potato plants and has a huge influence to immune response in potato under salinity stress, especially in early varieties of potato.

\section{References}

1. Yergaliyev T.M. et al. (2016) The involvement of ROS producing aldehyde oxidase in plant response to Tombusvirus infection. Plant Physiology Biochemistry. 109:36-44.

2. Aghaei K. et al. (2009) Potato responds to salt stress by increased activity of antioxidant enzymes. Journal Integrative Plant Biology. 51(12):1095-1103. 